\title{
A Review on Design of Integrated Healthcare Model through Performance Excellence Methodologies
}

\author{
Srideepti Ramayanam ${ }^{1}$, G.V.R.K Acharayulu² \& V.M. Prasad ${ }^{3}$ \\ ${ }^{1}$ Research Scholar, SMS/JNTUH, India \\ ${ }^{2}$ Professor of Management Sciences, SCM, Hyderabad Central University, India \\ ${ }^{3}$ Professor of Management, Al Yamamah University, Riyadh, KSA
}

Correspondence: Srideepti Ramayanam, Research Scholar, SMS/JNTUH, India, Corresponding author, Tel: +919160099001, Email: srideeptiramayanam@gmail.com

\begin{abstract}
Cost based care is evolving as a resolution to address increasing Healthcare costs, and to address the problem of clinical inefficiencies. 'Cost based care' therefore is designed to be patient centric. While 'Cost based care' helps in addressing the challenge of rising costs and making the care more affordable, it comes with its own set of challenges for providers as they are paid for better patient outcomes in an evidence based way. In the regimen of 'Cost based care' providers are grappling with reduced reimbursements. Providers are also required to track wide variety of measures to make the care more evidence based. Operations transformation for a healthcare systems means that it makes the processes, efficient, flexible and innovative to suit patient centric treatment models. To achieve this transformation by excluding wastes out of system, make the processes much more efficient, implementation of digital systems across the value chain of the hospital have become the area of focus. Shared Services alteration is a subclass of administrational transformation. It is has a lot of potential to smoke out costs, making operational processes much more efficient by rationalizing functions, like Human Resources, Pathology, Radiology, IT and Supply chain services at Hospitals. Administrational transformation aims to flush out costs, bring transformation in revenue cycle, and focus on Patient centric treatment modules. By implementing data visualization dashboards across the services would enable transparency and trust for patients.
\end{abstract}

Keywords: Unaffordable Healthcare Services, Interoperability, Technology in Healthcare Services, Data Visualization Dashboards.

\section{Introduction}

Costs of Healthcare organizations across the Globe are escalating faster than the GDP growth making the Healthcare unreasonable. Healthcare and Life Sciences organizations are committed to enhancing the lives and well-being of people around the world, while people are hoping to receive excellent service quality tend to prefer private hospitals or even travel across globe for better quality and cost-effective treatments. Quality of services has become a pivotal point in the Healthcare industries today. Hospitals and Healthcare systems continue to produce services that vary in quality, leading to inefficient processes and outputs, hence resulting in poor customer satisfaction. Healthcare organizations operating in the public sectors are experiencing increasingly low satisfaction from patients regarding the quality of services provided. Due to the result, Healthcare administrators face the challenge to advance the 
quality of services in their organizations. Based on the survey performed at different organizations, the outcome reflects that the teams are not able to keep its cost comparable, acceptable and approachable to many patients \& are unable to cope up with the denial of claims by the Insurance companies. There is a need to re-iterate on improving Health outcomes by providing Digital technologies \& Business transformation solutions to achieve patient satisfaction. The proposed integrated model demonstrates building domain knowledge, and expertise in Business, Process, and Management would enable Healthcare companies to focus on costs \& achieve process efficiencies.

\section{Literature Review}

A review of 490 articles across AJMC, Oxford, NCBI, Essential Hospitals, PCPCC journal publications has led to discussions with multiple stakeholders across industries. The existing system of health care quality improvement has increased the cost of medical treatment. To balance the quality and cost in the corporate sectors and to make the world class services available to every citizen has become a very challenging task to the present day administrators. The uncovered citizens are unable to avail of these medical facilities and crave for medical help. To achieve patient satisfaction by observing the four elements like patient's readiness, speed, instructions, coordination of arrangements. Other elements may include the inadequate treatment, discharge process, limited choice, post-acute care arrangements, transport issues, billing details and responsibility of discharge. To have effective hospital management the capacity planning, reviewing performances and action steps are to be managed appropriately.

\section{Methodology}

Empirical research was used to determine patients' perceptions and expectations of service quality. Moreover, data from different Healthcare systems will be gathered to understand the variation in cost \& quality of services rendered.

- LEAN Six Sigma concepts \& methodologies will be used to evaluate and improve the processes.

- The LEAN concept of identifying the Non-value adding steps are in the entire operations of health care systems that are contributing to additional costs are studied in detail by performing a value stream mapping of each process step that is critical to quality.

- DMADV approach of Six Sigma methodology was used in the present study

- Finally, the proposed model was created using multi-disciplinary teams

\section{Findings and Discussions}

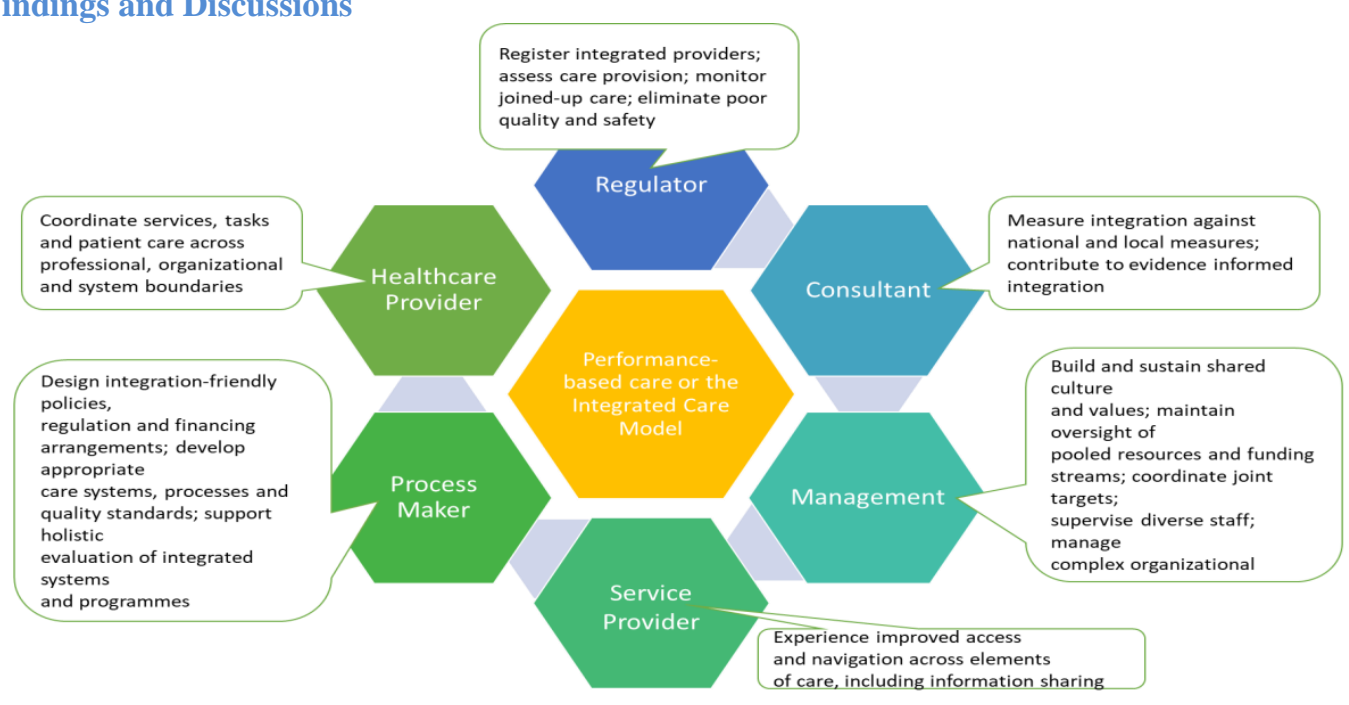

Fig.1. The outcome of reviewed proposed design of integrated Healthcare model through performance excellence methodologies

This model (Fig.1) has been articulated based on the local survey conducted across Healthcare Organizations. This model is a comprehensive approach that can lower costs, organise active processes, reduce errors in internal operations, and enhance care coordination. This model designed to results in better revenues, decrease costs and eliminates activities that are not adding value to these systems. The Healthcare institutions are progressively making affords to move towards patient-focused care delivery models. As a result, issues like patient engagement, care orchestration, and patient satisfaction are now major focus areas for transformation leaders. 
This model iterates the use of integrated Population statistics, Patient Interactions, Resource Utilization, Care Orchestration and organization Performance measurement. In each of this bucket, the Healthcare Systems need to identify and target the inhabitants, stratify and capture the risk. Once we accomplish, the receivers of care need to be engaged; then at each level, the processes need to be validated to remove possible repetitive tasks. By removing these repetitive tasks will then result in coordination with the payers and receivers of care to measure, map and articulate outcomes. Once the outcome achieved, these need to be fed back to the population statistics to create a benchmark of performance across the provider's space. A quarterly review of these metrics will result in achieving 'Performance-based care or the Integrated Care Model.'

The proposed model would be providing services that include but not limited to:

- Effective capture of medical history will eventually reduce patient wait times

- Reduced manual data entry effort would lead to improved staff productivity resulting in reduced risk of inefficiencies

- It would allow clinicians to focus on patient care and coordination for reduced length of stay at hospitals

- This model would lower the Total Cost of Healthcare as each of the providers would avoid costly point-topoint integrations with referring physician practices

- Timely and easy access to lab reports and trends ensured that referring physicians continue to drive patient traffic based on clinical condition

- Instantaneous monitoring of operational metrics at labs enabled continuous improvement in business outcomes

- Technology offers a unique amalgam of solutions to help the organizations to enhance the Patient experience, drive out prices and to improve business agility

However, lack of interoperability podium among Healthcare Systems and limited access to consolidated patient records are significant uphill tasks for moving ahead this model. Additionally, the Healthcare industry lacks secure and intuitive communication and collaborative or interoperable tools. Generally, the clinical staff is overwhelmed by technology rather than focusing on what's essential in patient care.

Another major contributing factor to this problem is that all these capabilities come at great capital and time investment. These are further decelerating the pace of this change.

Nevertheless, in order to withstand transformations over time, integrated care models require actions that extend from organizational, functional, professional and service delivery levels up to transformations on system level addressing each area of operational management. For instance, the adoption of multidisciplinary styles goes beyond the organization of providers vs. payers and requires alignment of healthcare policies at the technology and systemlevel. Given the performance-based evidence system, it becomes indistinct that establishing integrated care is a multi-layered and long-term process involving high capital investments.

\section{Conclusion}

The literature reviewed during the research provides evidence that integrated care models are introduced and implemented as a change management strategy. Reviewed literature also show affluence of implemented and evaluated integrated care models that range from individual, disease-specific models and models that embrace entire masses. Integrated healthcare delivery is a framework to reinforce people-centered health care providers towards the advancement of a comprehensive delivery mechanism of quality services across the course. The proposed design needs modification according to the multidimensional needs of the receivers of care and the individuals that provide and coordinate multidisciplinary team across of providers/payers space working across settings and levels of care. It should be thoroughly managed to ensure optimal outcomes and the appropriate use of resources based on the best available facts, with continuous feedback mechanisms to improve performance and to hold upstream causes of illness and to promote well-being performance improvement methodologies.

Healthcare Organization's covenant with the industry challenges, regulatory concerns, safety and comfort of care receivers. These challenges can be addressed by integrating Technology into healthcare practice and uniquely position themselves to orchestrate care that is 'Performance-based care or the Integrated Care Model'. There is remarkable consistency in the evidence for some of the key areas of such a strategy. The model further emphasizes the many different generic components described above observed as core components of 'Performance-based care or the Integrated Care Model'. 
Acknowledgements

The authors wish to thank the Healthcare organizations; its employees and the patients who have contributed to this research and model creation

References

Brett E. Trusko, Carolyn Pexton, Jim Harrington, Praveen Gupta. Improving Healthcare Quality and Cost with $6 \sigma$. Publisher: Financial Times Press.

Robert Barry, PhD, Amy C. Murcko, APRN, Clifford E. Brubaker, PhD Co. The $6 \sigma$ Book for Healthcare:Improving Outcomes by Reducing ErrorsPublisher: American Society for Quality.

Donald W. Benbow \& T. M. Kubiak (2 edition (January 7, 2009)). The certified $6 \sigma$ Black Belt Handbook. Publisher: ASQ Quality Press;

Viswadeep Katri (2009). Benchmark $6 \sigma$ Green Belt Handbook. Publisher Benchmark

Thomas M. Cappels (1999). Financially Focused Quality. Publisher CRC Press LLC

Sai Kumar (2011). QAI 6 $\sigma$ Black Belt Handbook. Publisher QAI

Michael L. George (Author), David Rowlands (Author), Bill Kastle (Author) (November 17, 2003). What is Lean Six Sigma. Publisher: McGraw-Hill Education;

Woodard TD. Addressing variation in hospital quality: is Six Sigma the answer? J Healthc Manag. 2005;50(4):226-36.

Jabnooun, N. and Chaker, M. (2003), Comparing the quality of private and public hospitals, Managing Service Quality, Vol. 13, No. 2, pp. 290-9.

Sewell, N. (1997), Continuous quality improvement in acute health-care: creating a holistic and integrated approach, International Journal of Health Care Quality Assurance, Vol. 10, No. 1, pp. 20-6.

Reidenbach, E. and Sandifer-Smallwood, B. (1990), Exploring perceptions of hospital operations by a modified SERVQUAL approach, Journal of Health Care Marketing, Vol. 10, No. 4, pp. 47-55.

Falter, Elizabeth (Betty)Apr-Jun (2008). Lean-6 $\sigma$ for Healthcare ... A Senior Leader Guide to Improving Cost and Throughput.Nursing Administration Quarterly,Vol. 32 Issue 2, p168-170, 3p

Bowers, M. R., J. E. Swan, and W. F. Koehler. (1994). "What Attributes Determine Quality and Satisfaction with Health Care Delivery?" Health Care Management Review 19 (4): 49-55.

Chong, Y., N. Unklesbay, and R. Dowdy. (2000). "Clinical Nutrition and Foodservice Personnel in Teaching Hospitals Have Different Perceptions of Total Quality Management Performance." Journal of American Dietetic Association 100 (9): 1044.

Cole, D. A. (1999). "Creating Outcomes with Redesign Efforts.” AORN Journal 70 (3): 406.

Dowd, S. B., and E. Tilson. (1996). "The Benefits of Using CQI/TQM Data (Continuous Quality Improvement/Total Quality Management)." Radiologic Technology 67 (6): 533-37.

Johnstone, P. A. S., J. A. W. Hendrickson, A. J. Dernbach, A. R. Secord, J. C. Parker, M. A. Favata, and M. L. Puckett. (2003). "Ancillary Services in Health Care Industry: Is 6 $\sigma$ Reasonable?" Quality Management in Health Care 12 (1): 53- 63.

Institute of Medicine. (2001). Crossing the Quality Chasm: A New Health System for the 21st Century. Washington, DC: National Academies Press.

Locock, L. (2003). "Healthcare Redesign: Meaning, Origins and Application." Quality and Safety in Health Care 12 (1): 53-57.

Longest, B. B, J. S. Rakich, and K. Darr (eds.). (2000). Managing Health Services Organizations and Systems, the 4th Edition. Baltimore, MD: Health Professions Press.

Luck, J., and J. W. Peabody. (2000). "Improving the Public Sector: Can Reengineering Identify How to Boost Efficiency and Effectiveness at a VA Medical Center?" Health Care Management Review 25 (2):

Luke, R. D., J. C. Krueger, and R. E. Modrow. (1983). Organization and Change in Health Care Quality Assurance. Rockville, MD: Aspen Systems Corporation.

McConnell, P., and V. G. Ciotti. (1995). "Applyin TQM/CQI Principles to Information Systems Selection."Healthcare Financial Management 49 (5): 48-52.

McLaughlin, C. P., and A. D. Kaluzny. (1994). Continuous Quality Improvement in Health Care. Gaithersburg, MD: Aspen Systems Corporation.

Pyzdek, T. (2001). " $6 \sigma$ and Beyond." Quality Digest. [Online article; retrieved 11/29/04.] http://www.qualitydigest.com /feb01/html/sixsigma.html.

Revere, L., and K. Black. (2003). "Integrating $6 \sigma$ with Total Quality Management: A Case Example for Measuring Medication Errors." Journal of Healthcare Management 48 (6): 377-91. 
Rowell, P. (2004). “Appropriateness of Care: The Case for Changing the Focus of 'Quality' Measurement." Quality Management in Health Care 13 (3): 178-82.

Samuels, D. I., and F. L. Adomitis. (2003). " $6 \sigma$ Can Meet Your Revenue-Cycle Needs: $6 \sigma$ Is Far from Being the Latest Quality Improvement Fad; It Is a Proven Technique Grounded in Principles that will Endure As Long As There Are Processes that Require Improvement." Healthcare Financial Management 57 (11): $70-75$.

Walston, S. L., and R. J. Bogue. (1999). “The Effects of Reengineering: Fad or Competitive Factor?” Journal of Healthcare Management 44 (6): 456

WHO Regional Office for Europe. Health 2020: a European policy framework is supporting action across government and society for health and well-being. Copenhagen: WHO Regional Office for Europe; 2013

Singh D, Ham C (2006). Improving Care for People with Long-term Conditions: A Review of UK and International Frameworks. Health Services Management Centre: Birmingham and NHS Institute for Innovation and Improvement;

Agency for Healthcare Research and Quality. Defining the PCMH | PCMH Resource Center [website] (https://pcmh.ahrq.gov/page/defining-pemh)

Shaw S, Rosen R, Rumbold B (2011). What is integrated care? An overview of integrated care in NHS. Nuffield Trust;

Hébert R, Durand PJ, Dubuc N, Tourigny A (2003). PRISMA: a new model of integrated service delivery for the frail older people in Canada. Int J Integr Care.; 3(1)

Kodner DL, Spreeuwenberg C (2002). Integrated care: meaning, logic, applications, and implications - a discussion paper. Int J Integr Care. Nov 14; 2 (4)

\section{Copyrights}

Copyright for this article is retained by the author(s), with first publication rights granted to the journal.

This is an open-access article distributed under the terms and conditions of the Creative Commons Attribution license (http://creativecommons.org/licenses/by/4.0/) 